\title{
CONCEPÇÕES EMBASADORAS DA FORMAÇÃO CONTINUADA NOS ANOS FINAIS DA REDE PÚBLICA DE ENSINO DO DISTRITO FEDERAL
}

\author{
THIAGO GONÇALVES FERREIRA DO NASCIMENTO ${ }^{1}$
}

\begin{abstract}
${ }^{1}$ Mestrando em educação do Programa de Pós-graduação da Faculdade de Educação da Universidade de Brasília - UnB e membro do Grupo de Estudos e Pesquisas sobre Formação e Atuação de Professores e Pedagogos - GEPFAPE, Professor de educação básica da Secretaria de Estado de Educação do Distrito Federal desde 2005.
\end{abstract}

\section{RESUMO}

O presente artigo tem como objetivo identificar as concepções epistemológicas, assim como as visões de homem, mundo, educação e sociedade que embasam a formação continuada nos anos finais da rede pública de ensino do Distrito Federal. Para tanto, debate os principais conceitos que têm embasado os projetos de formação docente ao longo dos anos, como, por exemplo, o referencial do professor pesquisador/reflexivo, o desenvolvimento profissional docente, a epistemologia da prática e a epistemologia da práxis e analisa as concepções presentes nos documentos oficiais que embasam a formação continuada na etapa dos anos finais, em especial, as Diretrizes Pedagógicas para a Organização Escolar do $3^{\circ}$ Ciclo para as Aprendizagens e as recém lançadas Diretrizes de Formação Continuada da Secretaria de Estado de Educação do Distrito Federal. Para realizar o debate, utiliza como referencial teórico os construtos de Santos (2010), Alvarado-Prada, Freitas e Freitas (2010), Alferes e Mainardes (2011), Curado Silva (2008, 2011 e 2018), entre outros.

Palavras-chave: Formação continuada; Anos finais do ensino fundamental; Concepções; Epistemologia da práxis; Formação crítico-emancipadora.

\section{THE CONCEPTS THAT UNDERLIE CONTINUING EDUCATION IN THE FINAL YEARS OF THE PUBLIC SCHOOL SYSTEM IN THE FEDERAL DISTRICT}

\begin{abstract}
This article aims to identify the epistemological conceptions, as well as the visions of man, world, education and society that base the continued formation in the final years of the public network of education of the Federal District. Therefore, debate key concepts that have grounded the teacher training projects over the years, for example, the reference of the researcher / reflective teacher, teacher professional development, the epistemology of practice and epistemology of practice, and analyzes the present
\end{abstract}


concepts in official documents that support continuing education in the step of final years, in particular the Pedagogical Guidelines for School Organization of the 3rd Cycle for Learning and the newly released guidelines of Department of continuing Education of State of Education of the Federal District . In order to carry out the debate, it uses as theoretical reference the constructs of Santos (2010), Alvarado-Prada, Freitas and Freitas (2010), Alferes and Mainardes (2011), Curado Silva (2008, 2011 and 2018), among others.

Keywords: Continuing education in the final years of elementary school; Professional development; Conceptions. Epistemology of praxis; Critical-emancipatory formation.

\section{INTRODUÇÃO}

Ao se retratar a educação, sempre profícuo será o debate, uma vez que, enquanto atividade fundamental intrinsecamente ligada à ontológica categoria trabalho, é o processo por meio do qual, desde os primórdios da existência humana, reproduz-se, desenvolve e transforma-se a sociedade, garantindo-se às gerações mais novas o aprendizado da experiência acumulada pelos homens ao longo do tempo.

A escola, enquanto instituição social tida como lócus privilegiado de realização do processo educativo, possui uma função social de extrema relevância, ao passo que se vê imersa num complexo emaranhado de interesses antagônicos provenientes de uma sociedade dividida em classes, regida sob a égide do capital.

À medida que os modos de produção na sociedade capitalista se complexificaram, as relações de produção modificaram-se e alteraram os paradigmas da relação capital-trabalho, o que impactou as relações sociais e, por conseguinte, os direcionamentos das instituições sociais. Passando do modelo Fordista/Taylorista ao Toyotista, ancorado no regime de acumulação flexível e na premissa do aprender a aprender, o capital, de alguma forma, acaba por relegar à educação a responsabilidade pela capacidade de desenvolvimento, tanto social quanto econômico, o que impacta o trabalho pedagógico em suas múltiplas dimensões, tanto a histórico-ontológica, quanto a pedagógica, a social e a política (FUENTES e FERREIRA, 2017), acarretando a necessidade de se (re) pensar os arranjos em que ocorre tal trabalho, de maneira a atender as exigências da sociedade como um todo ao passo que se atenda também aos anseios dos indivíduos, tarefa cada vez mais difícil num mundo globalizado que se desenvolve tecnologicamente num ritmo cada vez mais veloz. 
Ante tal demanda, a formação docente ganha destaque e acentua o debate acerca do desenvolvimento profissional do professor e os processos pelos quais este profissional chegaria a tal desenvolvimento. Nesse sentido, cumpre observar a importância atribuída à formação continuada.

Segundo Santos (2010), há quatro premissas que servem de sustentação para políticas e práticas de formação continuada. A primeira diz respeito aos discursos produzidos sobre a melhoria da qualidade do ensino, tendo o professor como protagonista dos projetos educativos; a segunda tem relação com a lógica pautada na defesa da qualificação profissional como caminho para o professor adequar-se às transformações científicas e tecnológicas requisitadas pela sociedade do conhecimento; a terceira relaciona-se à dimensão epistemológica, que define uma perspectiva de formação continuada assentada na reflexão sobre a prática pedagógica; e, por fim, um forte discurso de valorização do magistério.

A depender da lógica subjacente às políticas e às práticas de formação continuada, seja acadêmica, instrumental, economicista/mercadológica ou de desenvolvimento profissional, diferentes matrizes teóricas as orientarão, cada uma com expectativas de realização do trabalho docente, modelo de formação e perfil de professor idiossincráticos, expressando objetivos e metas a serem alcançados, os quais se materializarão por meio da prática pedagógica, exprimindo assim finalidades e princípios construídos por instituições e atores sociais motivados por interesses políticos e pedagógicos subjacentes a um determinado contexto socioeducacional.

Compõem o rol de preceitos legais que norteiam o projeto de formação continuada nos anos finais do Ensino Fundamental da rede pública de ensino do DF a Lei 9.394/96 - atual Lei de Diretrizes e Bases da Educação Nacional, a Lei 13.005/2014 - atual Plano Nacional de Educação, a Lei 5.499/2015 - atual Plano Distrital de Educação, a Resolução CNE/CP 01/2002 - que institui as Diretrizes Curriculares Nacionais para a formação de professores da educação básica, a Resolução CNE/CP 02/2015 - que define as Diretrizes Curriculares Nacionais para a formação inicial e continuada, o Decreto 8.752 - que dispõe sobre a Política Nacional de Formação dos Profissionais da Educação básica, e, com cunho pedagógico de maior especificidade quanto às peculiaridades educacionais do DF, as Diretrizes Pedagógicas para a Organização Escolar para o $3^{\circ}$ Ciclo para as Aprendizagens, O Currículo em 
Movimento, as Diretrizes de Avaliação e, mais recentemente, as novíssimas Diretrizes de Formação Continuada da Secretaria de Estado de Educação do Distrito Federal.

Assim sendo, importa saber quais os pressupostos imbricados neste projeto de formação continuada para se compreender quais as concepções de homem, mundo, educação e sociedade às quais advoga, no intento de desvelar que cidadão/profissional se deseja formar, para que sociedade e com que modelo de formação/educação.

\title{
2 DESENVOLVIMENTO PROFISSIONAL DOCENTE E FORMAÇÃO CONTINUADA
}

Segundo Alvarado-Prada, Freitas e Freitas

\begin{abstract}
a formação, como um caminho de diversas possibilidades, permite às pessoas que o transitam desenvolver-se, construir as relações que as levam a compreender continuamente seus próprios conhecimentos e os dos outros e associar tudo isso com suas trajetórias de experiências pessoais. Assim, a formação docente é uma contínua caminhada dos profissionais da educação, em cujo caminhar atuam todas as suas dimensões individuais e coletivas de caráter histórico, biopsicossocial, político, cultural, próprias de seres integrais e autores de sua própria formação (ALVARADO-PRADA, FREITAS e FREITAS, 2010, p. 370).
\end{abstract}

Marin (1995), ao analisar as concepções utilizadas na temática da educação continuada de profissionais da educação no Brasil, identificou o uso dos termos: reciclagem, treinamento, aperfeiçoamento, capacitação, educação permanente, formação contínua e educação continuada.

Ao se referirem à análise de Marin, Alferes e Mainardes indicam que

enquanto "reciclagem" referia-se a mudanças mais radicais para o exercício de uma nova função, ocasionando a implementação de cursos de formação continuada rápidos e esporádicos, "treinamento" tinha o foco voltado para a capacidade de o indivíduo realizar uma determinada tarefa através da modelagem de comportamento. O termo "aperfeiçoamento" significava tornar perfeito ou mais perfeito, ou ainda completar ou acabar o que estava incompleto, enquanto "capacitação" tinha uma conotação de tornar capaz e habilitar (ALFERES e MAINARDES, 2011, p.5).

Os autores evidenciam que "a concepção e as finalidades da formação continuada de professores no Brasil foram mudando ao longo do tempo, de forma bastante ligada ao contexto econômico, político e social do país (ALFERES e MAINARDES, 2011, p.3) ". Assim sendo, a concepção de treino de destrezas e técnicas foi sendo superada pelo entendimento de que a aprendizagem contínua é importante para o desenvolvimento profissional docente e da sociedade como um todo. 
No contexto de reformas educacionais que se intensificaram a partir da década de 1990, sobretudo após a promulgação da atual Lei de Diretrizes e Bases - Lei 9.394/96, ampliou-se consideravelmente o debate acerca da formação de professores, entendendo-se que a função social do professor relaciona-se à da escola, a qual é uma instância social que, dentre outras, tem papel mediador num projeto de sociedade, projeto este que pode ser conservador ou transformador, e, por isso mesmo, também contraditório entre formar para o mercado de trabalho ou para uma perspectiva omnilateral. Buscou-se, na formação, romper com o paradigma da racionalidade técnica, no qual o professor é concebido como técnico e sua atividade profissional como aplicação de teorias e técnicas na solução de problemas, dirigida por uma racionalidade instrumental. Isto é, caminhou-se na direção do entendimento de que a função básica de ambos, professor e escola, deveria ser a formação do sujeito capaz de entender, interpretar e transformar o mundo em que vive e, ainda, oferecer o domínio de determinados conteúdos científicos e culturais, a fim de garantir a aprendizagem de conhecimentos, habilidades e valores necessários à socialização do indivíduo. As aprendizagens deveriam constituir-se em instrumentos e habilidades para que o sujeito compreenda melhor a realidade que o cerca, favorecendo sua participação em relações sociais cada vez mais amplas, possibilitando a leitura e interpretação das informações que cotidianamente são amplamente veiculadas, preparando-o tanto para a inserção no mundo do trabalho quanto para a intervenção crítica e consciente na realidade.

A questão que se impõe é: como fazer isto, sabendo que tanto instituições sociais, quanto sujeitos e suas realidades são marcados social, política, cultural e historicamente?

Em comum, os normativos legais citados no item anterior indicam como tentativa de resposta a esta indagação o processo de desenvolvimento profissional docente, levando em conta que "tal conceito tem uma conotação de evolução e continuidade que, em princípio, supera a justaposição entre formação inicial e continuada dos professores" (MARCELO GARCIA, 1992, p. 45).

Para Haideman (1990, p. 4), "o desenvolvimento profissional dos professores vai para além de uma etapa meramente informativa; implica adaptação à mudança com o fim de modificar as atividades de ensino-aprendizagem, alterar as atitudes dos professores e melhorar os resultados escolares dos alunos”. Fullan (1990, p.3) indica 
que "o desenvolvimento profissional de professores constitui-se como uma área ampla ao incluir qualquer atividade ou processo que tenta melhorar destrezas, atitudes, compreensão ou atuação em papéis atuais ou futuros”. Sparks e Loucks-Horsley (1990, pp. 234-235) afirmam que desenvolvimento profissional docente "refere-se a todo processo que melhora o conhecimento, destrezas ou atitudes dos professores". VillegasReimers (2003, p. 65) elucida que "o desenvolvimento profissional docente é o crescimento profissional que o professor adquire como resultado da sua experiência e da análise sistemática da sua própria prática”. Já Day (1999) evidencia que

\begin{abstract}
desenvolvimento profissional docente inclui todas as experiências de aprendizagem natural e aquelas que, planificadas e conscientes, tentam, direta ou indiretamente, beneficiar os indivíduos, grupos ou escolas e que contribuem para a melhoria da qualidade da educação nas salas de aula. É o processo mediante o qual os professores, sós ou acompanhados, reveem, renovam e desenvolvem o seu compromisso como agentes de mudança, com os propósitos morais do ensino e adquirem e desenvolvem conhecimentos, competências e inteligência emocional, essenciais ao pensamento profissional, à planificação e à prática com as crianças, com os jovens e com os seus colegas, ao longo de cada uma das etapas das suas vidas enquanto docentes (p. 4).
\end{abstract}

Bereiter e Scardamalia, discorrendo sobre o processo de evolução decorrente do desenvolvimento profissional, diferenciam o profissional principiante do que já evoluiu ao grau de perito, indicando que, enquanto o principiante possui uma estrutura de conhecimentos superficial, com uma ideia geral mas sem inter-relações, o perito tem uma estrutura de conhecimentos profunda e de multiníveis, com muitas conexões inter e intraníves (1986, p. 12); dessa forma, diferentemente do principiante, o perito saberia quando, porque e como utilizar o vasto conhecimento que possui numa situação concreta.

Nesse sentido, Bransford, Derry, Berliner e Hammerness (2005) diferenciam o perito rotineiro do perito adaptativo, uma vez que, para os autores, embora ambos aprendam ao longo da vida, o primeiro desenvolve um conjunto de competências que vai aplicando ao longo de sua trajetória, cada vez com mais eficácia, enquanto que o segundo tem uma maior disponibilidade para transformar as suas competências, aprofundá-las e ampliá-las continuamente. Evidenciando inovação e eficiência como dimensões relevantes no processo de desenvolvimento do professor e evolução a perito, o perito adaptativo estaria numa linha ascendente de convergência entre estas duas dimensões, numa categoria definida como "corredor de adaptabilidade ótima". 
Segundo Marcelo (2009), o desenvolvimento profissional docente, nas últimas décadas, assumiu as seguintes características:

\begin{abstract}
baseia-se no construtivismo, e não nos modelos transmissivos; [...] ao contrário das práticas tradicionais de formação, que não relacionam as situações de formação com as práticas em sala de aula, as experiências mais eficazes para o desenvolvimento profissional docente são aquelas que se baseiam na escola e que se relacionam com as atividades diárias realizadas pelos professores; [...] o professor é visto como um prático reflexivo, alguém que é detentor de conhecimento prévio quando acede à profissão e que vai adquirindo mais conhecimentos a partir de uma reflexão acerca da sua experiência. Assim sendo, as atividades de desenvolvimento profissional consistem em ajudar os professores a construir novas teorias e novas práticas pedagógicas (p. 11).
\end{abstract}

Os autores aqui mencionados apresentam uma questão em comum, todos assumem a perspectiva de desenvolvimento profissional docente pela epistemologia da prática. No intuito de romper com a instrumentalização, por vezes acrítica, advinda da formação consubstanciada num viés de racionalidade técnica, advogam em favor de uma reflexão da prática, enaltecendo esta, por meio da experiência, como construtora de um modelo melhor de formação de professores.

As Diretrizes Pedagógicas para a Organização Escolar do $3^{\circ}$ Ciclo para as Aprendizagens (etapa que corresponde aos anos finais do ensino fundamental) asseveram que a formação continuada é um dos elementos fundantes da organização escolar do Distrito Federal, que deve contribuir para a melhoria dos processos de ensinar, aprender, pesquisar e avaliar e que a perspectiva assumida é a do

\begin{abstract}
desenvolvimento profissional docente que contempla, além da formação, a valorização profissional e a melhoria das condições de trabalho num continuum que possibilita a revisão das trajetórias docentes de forma críticoreflexiva" . Nessa perspectiva, a formação continuada contribui para a apropriação e ou revisão de concepções e práticas pedagógicas, transformando-as em práxis por meio da reflexão crítica de situações e experiências de trabalho vivenciadas na própria escola e da atuação consciente dos docentes (DISTRITO FEDERAL, 2014a, p. 26-27).
\end{abstract}

Referenciadas em Nóvoa (1995), indicam que a formação desses profissionais deve se pautar pela perspectiva crítico-reflexiva que possibilite a construção de sua autonomia pessoal e pedagógica, o que não se dá (apenas) por acumulação (de cursos, de conhecimentos ou de técnicas), mas sim, por meio do trabalho de reflexão crítica sobre as práticas e da (re) construção permanente de uma identidade. Enfatizam que, no processo de ensinar e aprender, é preciso assumir posturas que favoreçam a pesquisa, a investigação e a reflexão crítica sobre a prática pedagógica, bem como estar aberto para 
questionar suas concepções, suas ações, sua visão de mundo e de ser humano. Ou seja, diferentemente dos autores que primam pela epistemologia da prática, assentam-se na formação continuada baseada num modelo de desenvolvimento profissional docente que enaltece a práxis como referência epistemológica, diferenciando-se assim dos modelos que valorizam a reflexão, mas apenas evocam sua utilização num viés pragmatista, trazendo em seu bojo a prática enquanto arquétipo epistemológico. Os pressupostos teóricos do Currículo em Movimento traduzem tal característica como o "Princípio da Unicidade entre Teoria e Prática”. Não associação, nem relação, mas unicidade (DISTRITO FEDERAL, 2014b, p.66).

\section{O PROFESSOR PESQUISADOR/REFLEXIVO E AS CONCEPÇÕES SUBJACENTES}

Segundo Curado Silva (2008), é possível se apontar três correntes que abordam o tema do professor pesquisador/reflexivo: uma, inspirada em John Dewey (1933) e que, contemporaneamente, tem como maiores expoentes Donald Schon (2000) e Kenneth Zeichner (1993), oriunda dos EUA; outra, inspirada em Kurt Lewin (1972), oriunda da Inglaterra e que tem como representantes Lawrence Stenhouse (1987 e 2003) e seu seguidor John Elliot (1998); e ainda, oriunda da Austrália, uma terceira que tem como representantes Wifred Carr e Stephens Kemmis (2001), que também se origina das concepções de Lewin, mas se aproximam mais da teoria comunicativa de Habermas (1998).

Embora Dewey, na década de 1930, já discutisse o professor enquanto inovador, reflexivo e autodirigido, a literatura associa a Stenhouse (1975) a origem do termo e noção de professor-pesquisador. Juntamente com seu "discípulo", John Elliot, que viria posteriormente a sucedê-lo, dirigiu o Centro de Investigação Aplicada em Educação CARE da Universidade East Anglia, no Reino Unido, e compartilhava da ideia de que as pesquisas poderiam resolver diretamente os problemas do cotidiano, envolvendo os professores das escolas com um objetivo centrado e pragmático: melhorar o ensino nelas praticado.

As atividades desses autores se centraram no estudo do currículo. Em decorrência da concepção de currículo que defendiam, desenvolveram um amplo e 
notável conjunto de trabalhos sobre a possibilidade de utilizar os estudos das escolas e aulas para que os próprios docentes pudessem investigar e desenvolver suas ideias acerca do currículo possível na sala de aula.

No tocante à compreensão da relação teoria e prática, na proposta de Stenhouse (1993), o que guia a ação de investigação do professor é o seu senso crítico, que se constitui em uma ética e uma estética configuradas pela racionalidade prática. Nessa perspectiva, a prática se torna fundamento e referência da verdade da teoria que a reflete e deve ser comprovada na utilidade a que serve.

De acordo com Curado Silva (2008), ao definir a pesquisa do professor, Stenhouse (1993) se remete a uma epistemologia fenomenológica da relação sujeitoobjeto na perspectiva da tradição naturalística de observação e da etnografia. "[...] Para o autor, o caminho para a produção de conhecimentos do professor sobre sua prática é a pesquisa-ação, que encontra justificativa em um campo substantivo da ação - no caso, a educação - mais que puramente em termos de pesquisa" (p. 100).

John Elliot (2000), que deu continuidade aos projetos iniciados por Stenhouse no CARE, ao conceituar a "filosofia da prática", diz que a validade das teorias e hipóteses geradas na investigação-ação não depende da comprovação de provas científicas, mas de sua utilidade em ajudar as pessoas a agirem de um modo melhor. Para ele, o objetivo fundamental da investigação-ação é melhorar a prática e a partir dela gerar conhecimentos, cuja produção e utilização são subordinadas a esse objetivo.

Segundo Curado Silva (2008, p. 101), “os princípios da pesquisa-ação que aparecem na obra dos dois autores caracterizam-se por um posicionamento diante da ação, com base numa reflexão autocrítica objetiva e em uma avaliação de resultados”. Ainda de acordo com a autora, a proposta de formação de professores advinda das concepções desses autores pode ser caracterizada como humanista; entretanto, a forma de pesquisa proposta por eles pode acabar por contribuir para um círculo vicioso que recorre quase sempre à pura narrativa da experiência e da realidade, sem revelar suas mediações e contradições.

Um outro paradigma que trata da reflexão na formação profissional tem em Donald Schon (2000) um de seus principais expoentes. Trata-se da concepção de formação profissional prática, ou "epistemologia da prática", que decorre do princípio de formação do "[...] aprender a fazer fazendo" (p. 20), e é centrada no saber 
profissional, tendo a reflexão na ação como ponto de partida para responder a conflitos e situações de incerteza no cotidiano profissional.

Tardif (2002) aponta a epistemologia da prática profissional, cuja finalidade seria revelar os saberes que englobam "os conhecimentos, as competências, as habilidades e as atitudes, aquilo que muitas vezes foi chamado de saber, saber-fazer e saber-ser" (p. 11), visando compreender a natureza desses saberes, assim como o papel que desempenham tanto no processo do trabalho docente quanto na identidade profissional dos professores, como oposição à racionalidade técnica.

$\mathrm{Na}$ concepção da epistemologia da prática, a valorização da reflexão na formação profissional entende o conhecimento profissional enquanto processo no qual um resultado inesperado pode levar à reflexão (reflexão-na-ação), que tem uma função crítica, questionando a estrutura de pressupostos do ato de conhecer-na-ação. O que diferencia este tipo de reflexão de outras é a sua imediata significação para a ação. É peculiar o fato de que, no processo de reflexão-na-ação, as "apreciações e crenças estão enraizadas em mundos construídos por nós mesmos, que viemos a aceitar como realidade" (SCHON, 2000, p. 39) e não a ideia de simples aplicação de teorias e técnicas derivadas de pesquisa científica à solução de problemas da prática. A partir dessa concepção, o processo de formação se dá por meio de uma conversação reflexiva que, ao contrário do modelo da racionalidade técnica, não se baseia nas dicotomias entre meios e fins, pesquisa e prática, fazer e conhecer, já que a prática se assemelha à pesquisa, os meios e fins são concebidos de forma interdependente nos problemas, assim como o conhecer e fazer são inseparáveis.

Embora também trabalhe a proposta de professor reflexivo a partir dos construtos de Dewey (1933), Zeichner (1993) demarca profundas diferenças conceituais na concepção que orienta suas proposições, sobretudo em relação a Schon (2000), uma vez que busca elementos mais filosóficos e menos instrumentais para fundamentar seu trabalho, como a questão da democracia, do desenvolvimento profissional e da reconstrução social.

Segundo Curado Silva (2008, p.112), a obra de Kenneth Zeichner visa à valorização do professor por meio do reconhecimento de que a produção de conhecimento sobre o que é ensino de qualidade "não é propriedade exclusiva da universidade, que 'pensa' a educação, mas também dos professores que têm boas teorias 
e práticas e podem contribuir com avanço da qualidade no ensino de educação básica". Para este autor, o professor é o único capaz de examinar sua prática, uma vez que somente o detentor da prática está em condições de refletir sobre ela (o que constitui uma ciência da prática) - visão que é contestada por Curado Silva (2008).

Descrevendo as tradições de ensino reflexivo, indica que, na perspectiva de reconstrução social, o professor deve levar em conta tanto a sua própria prática, como também deve estar atento às condições sociais nas quais sua prática está inserida. A reflexão, no caso, também deve auxiliar o professor a examinar as consequências políticas e sociais de seu ensino, questionando equidade social e justiça social dentro e fora da sala de aula.

\title{
Curado Silva assim o categoriza:
}

\begin{abstract}
sua investigação centra-se em compreender e explicitar a maneira como os professores aprendem a ensinar e em como ajudá-los a ensinar, tendo como ponto de partida a problematização da prática do professor e a utilização da pesquisa-ação, a fim de que se tornem "agentes ativos do seu próprio desenvolvimento profíssional e da definição do funcionamento das escolas" [...] Paralelamente à causa da profissionalização dos professores, envida esforços para a "construção de sociedade mais justa e decente" [...] Embora reconheça que os dois aspectos (profissionalização de professores e sociedade mais justa) não estão necessariamente ligados, este tem sido o grande tema do seu trabalho: "a tentativa de relacionar o desenvolvimento do professor com a luta pela justiça social para todas as crianças” [...] (CURADO SILVA, 2008, p. 114).
\end{abstract}

Para a autora, pautando-se pelos processos de desenvolvimento e aprendizagem de base construtivista, sistematizados a partir dos construtos de Piaget, Zeichner (1998), entende o professor como investigador, não no sentido da pesquisa acadêmica, mas como atitude investigativa, cujo papel é "mais auxiliar os alunos a construir o saber do que transmitir conhecimentos" (CURADO SILVA, 2008, p. 117).

Numa outra corrente de pensamento acerca do professor pesquisador/reflexivo, a qual Curado Silva denominou de "perspectiva social crítica", situam-se Wilfred Carr e Stephen Kemmis. As propostas destes autores fundamentam-se em contribuições da Escola de Frankfurt, sobretudo em Habermas (1997), utilizam referencial na crítica ideológica de Marx (1984), no processo de conscientização de Freire (1993) e ainda na leitura psicanalítica do sujeito contemporâneo.

A proposta de Carr e Kemmis (1988) situa os saberes docentes, a formação de professores e a prática pedagógica num contexto de práxis emancipatória: defendem uma relação dialética entre teoria e prática e vinculam o projeto de pesquisa-ação a um 
projeto emancipador de sociedade, que estaria orientando a direção e o sentido em que a prática deve ser melhorada. Diferentemente de Zeichner (1993), consideram a pesquisaação colaborativa apenas quando o grupo de pesquisadores escolhe coletivamente o problema a ser investigado.

Esses autores afirmam que a função da pesquisa não é produzir melhores teorias e nem práticas mais eficazes, mas fazer com que a prática seja enriquecida com a reflexão crítica sem ao mesmo tempo deixar de ser prática (CARR; KEMMIS, 1988). Concebendo a prática pedagógica como práxis social, argumentam que, no trabalho docente, o professor utiliza diferentes saberes e linguagens, como o senso comum, a sabedoria popular, o conhecimento proficiente, contextual, profissional, as teorias educativas, as teorias morais e sociais e as perspectivas filosóficas gerais.

Entretanto, como bem assevera Curado Silva (2008), a interpretação de educação como práxis nestes autores filia-se a Habermas (1997), que inclui o trabalho como a interação ou ação comunicativa, práxis comunicativa. As categorias centrais da tese marxiana: trabalho, relações de produção, classe, não são tomadas por Carr e Kemmis (1988) como objeto de análise nem de referência, para pensar a formação do professor reflexivo/pesquisador.

Para além destas três correntes, há outros estudos que também demonstram preocupação com as estratégias práticas dos docentes, ressaltando a importância do professor como centro de sua própria formação, atuando como sujeito ativo na pesquisa de sua própria prática docente, ou como intelectual transformador. Tendo como referência os Estudos Culturais, as propostas de formação decorrentes desta perspectiva incluem discussões sobre poder, linguagem, cultura e história e enaltecem o professor como intelectual-crítico. Segundo Curado Silva (2008), os principais autores que representam essa linha de pensamento são: Henry Giroux (1986), Tardif (1991), Shulman (1997), José Gimeno Sacristán (1998), Angel L. Pérez Gómez (1998), Francisco Imbernón (2000) e Perrenoud (2001).

Curado Silva (2018) indica que os processos de pesquisa e reflexão são bastante importantes, entretanto, é preciso se tomar o professor enquanto sujeito sócio-histórico, que, como trabalhador da educação, necessita ter elementos teórico-metodológicos para realizar sua atividade de forma crítica e politizada, levando em consideração as relações de poder desde o espaço da escola até o contexto mais amplo, a fim de interferir na 
realidade. Argumenta que é preciso se superar os modelos de formação de professores pautados na racionalidade técnica na e para a epistemologia da prática, a partir da indissociabilidade entre teoria e prática qualificada na atividade do trabalho docente, referenciada na epistemologia da práxis, práxis revolucionária, embasada na perspectiva crítica emancipadora de formação, que compreende que a educação para emancipação deve ser

crítica no sentido da análise e síntese do resgate da verdadeira história como ser humano que está situado num contexto social e objetivo concreto, reconhecendo a possibilidade da construção da autonomia de um sujeito racional, que tem conhecimento e liberdade e que, coletivamente, pode romper com a estrutura social opressora e construir uma sociedade emancipada por lutas coletivas sociais. (CURADO SILVA, 2018, p. 333).

As diretrizes de formação continuada da Secretaria de Estado de Educação acolhem e corroboram essa visão:

\footnotetext{
é importante registrar a necessidade de se questionar ou de superar, mesmo que de forma parcial, uma das teorias que tem se apresentado de forma hegemônica nesse campo e nos estudos de formação, como a do professor reflexivo. [...] Assinalam-se portanto, nestas Diretrizes, possibilidades de superação dos limites presentes em concepções de formação profissional essencialmente instrumentais e centradas na experiência prática. Nesse, sentido, defende-se uma perspectiva que favoreça o desenvolvimento profissional a partir da formação teórica e em direção a um saber crítico e a uma ação ética, pautados nos ideais de autonomia e emancipação. (DISTRITO FEDERAL, 2018, p. 27-29).
}

Segundo o documento, é de se esperar que a formação continuada contribua para o desenvolvimento pessoal e profissional dos profissionais da educação, para que bem executem suas atividades de caráter pedagógico, técnico e/ou institucional. "Contudo, tal desenvolvimento deve se fortalecer em atitudes de profissionais agentes da e para a emancipação, tanto de si mesmos quanto daqueles que são, também, protagonistas do processo educativo: os estudantes e os membros da comunidade escolar interna e externa" (DISTRITO FEDERAL, 2018, p. 15).

\section{EPISTEMOLOGIA DA PRÁXIS, UM CAMINHO DE NOVAS POSSIBILIDADES}

As recém lançadas Diretrizes de Formação Continuada da Secretaria de Estado de Educação do Distrito Federal asseveram que a formação continuada fundamenta-se numa concepção de educação baseada nos pressupostos teóricos da Pedagogia 
Histórico-Crítica (SAVIANI, 2012, 2013) e da Psicologia Histórico-Cultural (VIGOTSKI, 2001, 2002, 2003), assim como na avaliação formativa” (DISTRITO FEDERAL, 2018, p. 33) e, como projeto de formação, assumem a concepção Críticoemancipadora, embasada em Curado Silva (2002, 2008, 2011, 2014, 2018) - que referencia-se, entre outros, em Marx, Gramsci e Vázquez - consubstanciada na epistemologia da práxis.

A práxis pressupõe uma indissociabilidade, uma união dialética entre teoria e prática, entre conhecimento e transformação. Sánchez Vázquez assim a caracteriza,

uma atividade material, transformadora e adequada a fins. Fora dela, fica a atividade teórica que não se materializa, na medida em que é atividade espiritual pura. Mas, entretanto, não há práxis como atividade puramente material, isso é, sem a produção de fins e conhecimentos que caracteriza a atividade teórica (2011, p. 239).

Na concepção crítico-emancipadora, que entende a realidade como contraditória e dialética, a formação de professores, por meio da práxis, aspira a uma formação do sujeito histórico baseada em uma relação indissolúvel entre a teoria e a prática, a ciência e a técnica, constituída no trabalho e que garanta a esses sujeitos a compreensão da realidade sócio-econômico-política e que sejam capazes de orientar e transformarem as condições que lhes são impostas (CURADO SILVA, 2018).

Segundo as Diretrizes, a formação dos profissionais da educação

\begin{abstract}
deve transcender a ideia de centrar-se exclusivamente na prática profissional como elemento de construção de conhecimentos, voltando-se à compreensão das restrições impostas por essa prática a partir da apropriação e da produção teórica como elementos do desenvolvimento profissional e pessoal. Nesse movimento, torna-se essencial a aquisição do conhecimento elaborado nas ciências, nas artes, na filosofia, na pedagogia e nas ciências da educação; torna-se essencial, também, o desenvolvimento de recursos que possibilitem aos profissionais refletir e produzir representações próprias acerca desses conhecimentos, em inter-relação com sua prática profissional. (DISTRITO FEDERAL, 2018, p. 35).
\end{abstract}

Assim sendo, o projeto de formação continuada dos profissionais da educação do Distrito Federal tem por objetivo favorecer possibilidades de construção de autonomia e emancipação dos sujeitos envolvidos no ato educativo, tornando-os capazes de entender, interpretar e transformar o mundo em que vivem. Para isso, incorpora princípios que são fundantes da perspectiva crítico-emancipadora: a categoria trabalho; a relação dialética de unicidade entre teoria e prática; e a pesquisa na e da formação continuada enquanto estratégia teórico-metodológica (DISTRITO FEDERAL, 2018, p. 49-50). 


\section{CONSIDERAÇÕES FINAIS}

Embasadas na Pedagogia Histórico-Crítica, na Psicologia Histórico-Cultural, na Epistemologia da Práxis e referenciando-se numa perspectiva Crítico-Emancipadora de formação docente, as concepções que subjazem o projeto de formação continuada da rede pública de ensino do Distrito Federal, incluindo-se o caso particular da etapa relativa aos anos finais do ensino fundamental, enaltecendo como princípios a categoria trabalho, a relação dialética e indissolúvel entre teoria e prática e a pesquisa enquanto estratégia na e da formação, consubstanciam a reflexão-crítica que possibilita a apropriação e revisão de concepções e práticas pedagógicas, de modo que se caminhe na direção de um desenvolvimento profissional docente que seja capaz de favorecer a construção da autonomia e emancipação dos sujeitos envolvidos no ato educativo.

Superando o viés que já foi hegemônico no ensino do DF, de ação-reflexãoação, indicam a construção de um modelo referenciado em prática social-teoria-prática social, baseado na práxis (reflexiva, revolucionária), transcendendo-se assim modelos pragmatistas centrados exclusivamente na prática profissional, para que se forme sujeitos, que são social, política e historicamente condicionados (mas não determinados), conscientes e capazes de reconhecer e compreender as mediações e contradições que compõem a totalidade dos contextos nos quais estão inseridos, no intento de desvelar a realidade que os cerca, capacitando-os a intervir e modificar conscientemente o mundo a sua volta.

\section{REFERÊNCIAS}

ALFERES, Marcia Aparecida.; MAINARDES, Jefferson. A formação continuada de professores no Brasil. Seminário de Pesquisa. Universidade Federal de Maringá, 2011.

ALVARADO-PRADA, L. E.; FREITAS, T. C.; FREITAS, C. A. Formação continuada de professores: alguns conceitos, interesses, necessidades e propostas. Revista Diálogo Educação, Curitiba, v. 10, n. 30, p. 367-387, 2010.

BRANSFORD, J.; DERRY, S.; BERLINER, D. \& HAMMERNESS, K. (2005). Theories of learning and their roles in teaching. In L. Darling-Hammond \& J. Bransford (eds.), Preparing teachers for a changing world. S. Francisco: Jossey Bass, pp. 40-87.

BEREITER, C. \& SCARDAMALIA, M. (1986). Educational relevance of the study of expertise. Interchange, 17, 2, pp. 10-19. 
CURADO SILVA, Kátia Augusta Pinheiro Cordeiro da. Professores com formação stricto sensu e o desenvolvimento da pesquisa na educação básica da rede pública de Goiânia: realidade, entraves e possibilidades. 2008. 292f. Tese de doutorado (Programa de Pós- Graduação em Educação) - Faculdade de Educação, Universidade Federal de Goiás, Goiânia, 2008. p. 90-134.

CURADO SILVA, Kátia Augusta Pinheiro Cordeiro da. A formação de professores na perspectiva crítico-emancipadora. Revista Linhas Críticas, vol.17, $\mathrm{n}^{\mathbf{o}}$ 32. Brasília: Universidade de Brasília/FE. 2011.

CURADO SILVA PINHEIRO CORDEIRO, Kátia Augusta. Epistemologia da práxis na formação de professores: perspectiva crítica emancipadora. Perspectiva, Florianópolis, v. 36, n. 1, p. 330-350, abr. 2018. ISSN 2175-795X. Disponível em: $<$ https://periodicos.ufsc.br/index.php/perspectiva/article/view/2175-

795X.2018v36n1p330>. Acesso em: 17 jul. 2018. doi:https://doi.org/10.5007/2175795X.2018v36n1p330.

DAY, Christopher. Desenvolvimento profissional de professores - os desafios da aprendizagem permanente. Tradução Maria Assunção Flores. Porto: Porto Editora, 2001. (Coleção Currículo, Políticas e Práticas).

DISTRITO FEDERAL. Secretaria de Estado de Educação. Diretrizes Pedagógicas para Organização Escolar do $3^{\circ}$ Ciclo para as Aprendizagens. Distrito Federal: Secretaria de Estado de Educação, 2014.

DISTRITO FEDERAL. Secretaria de Estado de Educação. Diretrizes de Formação Continuada. Distrito Federal: Secretaria de Estado de Educação, 2018.

ELLIOT, J. Recolocando a pesquisa-ação em seu lugar próprio e original. In: GERALDI, Corinta M.G.; FIORENTINI, Dario; PEREIRA, Elisabete M de A (Orgs). Cartografias do trabalho docente: professor (a) pesquisador(a). Campinas: Mercado das Letras-ALB, 1998. p.307-333.

FUENTES, R. C.; FERREIRA, L. S. Trabalho pedagógico: dimensões e possibilidade de práxis pedagógica. PERSPECTIVA, Florianópolis, v. 35, n. 3, p. 722-7337, jul/set. 2017.

FULLAN, M. (1990). Inovação em Desenvolvimento Pessoal e Desenvolvimento Institucional. In: B. Joyce (org.), Cultura Escolar Através do Desenvolvimento Pessoal. Virginia: ASCD, p. 3-25.

GIROUX. Henry. Os professores como intelectuais: rumo a uma pedagogia crítica. Porto Alegre: Artes Médicas, 1997, p 157-164.

HEIDEMAN, C. (1990). Introduction to staff development. In P. Burke et al. (eds.), Programming for staff development. London: Falmer Press, pp. 3-9. 
MARCELO, Carlos. Desenvolvimento Profissional Docente: passado e futuro. Sísifo. Revista de Ciências da Educação, 08, pp. 7-22. 2009.

NÓVOA, Antonio (Org.) Profissão professor. 2. ed. Porto, Portugal: Porto. 1995.

ROLDÃO. Maria do Céu. Função docente: natureza e construção do conhecimento profissional. Revista Brasileira de Educação. V. 12, n.34 jan/abr. 2007.

SANTOS, E. O dos. A formação continuada na rede municipal de ensino do Recife: concepções e práticas de uma política em construção. 2010. 365 f. Tese (Doutorado). Programa de Pós-Graduação em Educação, Universidade Federal de Pernambuco, Recife, 2010.

SAVIANI, D. Pedagogia histórico-crítica: primeiras aproximações. 8. ed. Campinas: Autores Associados, 2003.

SCHON, Donald. Educando o profissional reflexivo - um novo design para o ensino e a aprendizagem. Porto Alegre: Artes Médicas, 2000.

SPARKS, D. \& LOUCKS-HORSLEY, S. (1990). Models of Staff Development. In W. R. Houston (ed.), Handbook of Research on Teacher Education. New York: McMillan Pub., pp. 234-251.

TARDIF, Maurice. Saberes docentes e formação profissional. Petrópolis-Rj: Vozes, 2002.

VAZQUEZ. Adolfo Sanches. Filosofia da Práxis. Buenos Aires: CLASCO, 2011.

Villegas-Reimers, E. (2003). Teacher Professional Development: an international review of literature. Paris: UNESCO/International Institute for Educational Planning.

ZEICKNER , K. Para além da divisão entre professor-pesquisador e professor acadêmico. In:GERALDJ, Corinta M. G., FIORENTINI, Dario, e PEREIRA, Elisabete M. de A. Cartografias do Trabalho Docente. Campinas-SP: Mercado das Letras, 1998, p. 207-231. 